\title{
Beverages have an appreciable contribution to the intake of soluble dietary fibre: a study in the Spanish diet.
}

1

2 a Department of Metabolism and Nutrition, Instituto de Ciencia y Tecnología de 3 Alimentos y Nutrición (ICTAN-CSIC). Madrid, Spain.

4

\section{Elena Diaz-Rubio ${ }^{\mathrm{a}^{*}}$ and Fulgencio Saura -Calixto ${ }^{\mathrm{a}}$}

*Corresponding Author: M. Elena Diaz-Rubio, Department of Metabolism and

Nutrition, Instituto de Ciencia y Tecnología de Alimentos y Nutrición (ICTAN-CSIC). Madrid, Spain C/ José Antonio Novais, 10 Ciudad Universitaria, 28040 Madrid, Spain. Phone: 34 915445607. Fax 34 915493627. E-mail: medr@ictan.csic.es

\section{Abstract}

Beverages are generally not taken into account to determine the intakes of dietary fibre in diets. Soluble dietary fibre content was determined in common alcoholic and non alcoholic beverages - ranging from $0.18 \mathrm{~g} / \mathrm{L}$ in white wine to $9.01 \mathrm{~g} / \mathrm{L}$ in instant coffee - and their contribution to the dietary fibre intake in the Spanish Mediterranean diet was estimated at $2.13 \mathrm{~g} /$ person/day. It is concluded that beverages provide an appreciable amount of soluble dietary fibre in the diet, and the omission of its contribution may lead to underestimate dietary fibre intakes.

Keywords: dietary fibre, dietary intake, beverages, polysaccharides, soluble dietary fibre, Mediterranean diet. 
The literature and food composition tables provide comprehensive dietary fibre (DF) data on plant foods (Food Standards Agency 2004; Moreiras et al. 2007), but they generally report zero DF content for beverages because of analytical methodology limitations (Mañas et al. 1994). The intake of dietary fibre in diets is determined exclusively from vegetable food data because it is generally assumed that beverages do not contain dietary fibre. However, the processing of plant foods to obtain common beverages may solubilize an appreciable amount of soluble indigestible polysaccharides or dietary fibre (Diaz-Rubio \& Saura-Calixto 2009; Diaz-Rubio \& Saura-Calixto 2006; Diaz-Rubio \& Saura-Calixto 2007). Dietary fibre intakes (determined from solid plant food data) are estimated at around $20 \mathrm{~g} /$ person/day in Western countries, which is bellow the recommended allowances (25-35 g or 14g/1000 Kcal) (Buttriss \& Stokes, 2008; Lunn \& Buttiss, 2007). To our knowledge there are no studies on the contribution of beverages to DF intakes. The aim of this work was to determine soluble dietary fibre (SDF) in the most common beverages and to estimate their contribution to the intake of dietary fibre in a whole diet - in this case the Spanish Mediterranean diet-.

\section{Material and methods}

Individual beverages selected in this study (juices, alcoholic beverages, coffee, infusions, soft drinks and others) are representative of drinks most common in the Spanish market (MAPA 2009). The method for SDF determination has been previously reported (Diaz-Rubio \& Saura-Calixto 2006; Diaz-Rubio \& Saura-Calixto 2007). A simplified scheme of the methodology is shown in Figure 1. Calibration curves from monosaccharides profile (Figure 2) of the hydrolysed dietary fibre component of each beverage (obtained by gas-liquid chromatography analysis) were used to quantify SDF.

\section{Results and Discussion.}


The contents of SDF in fruit juices, alcoholic drinks, coffee and infusions and soft drinks are shown in table I. The beverages tested in this work, with the exception of soft drinks that present a negligible content, have an appreciable SDF amount, ranging from $0.18 \mathrm{~g} / \mathrm{L}$ in white wine to $9.01 \mathrm{~g} / \mathrm{L}$ in instant coffee .

In the alcoholic beverage group, beer and red wine had higher SDF contents $(2.08 \mathrm{~g} / \mathrm{L}$ and $1.91 \mathrm{~g} / \mathrm{L})$ than drinks such as cider $(0.23 \mathrm{~g} / \mathrm{L})$ and white wine $(0.18 \mathrm{~g} / \mathrm{L})$ which are elaborated without maceration, the lack of which dramatically limit the solubilisation of fibre. Instant or soluble coffee (freeze-dried coffee infusion) $(9.01 \mathrm{~g} / \mathrm{L})$ and cocoa drink (7.36 g/L) showed the highest SDF content (table I).

Spirits and drinks obtained by distillation do not contain SDF. As it was expected, soft drinks showed a negligible amount of SDF probably coming from some additive; only orange soft drink contained a certain amount of SDF $(0.24 \mathrm{~g} / 1)$.

Figure 2 shows the monomer composition of SDF, which represent their main polysaccharides . For instance, mannose $(32.19 \%)$ and galactose $(27.15 \%)$ were the main monosaccharides found in red wine, suggesting that arabinogalactan and mannans are the most important SDF components. On the other hand the presence of fucose in apple juice could indicate that fucogalactoxyloglucane is part of the SDF in this juice (Schols et al. 1995) (figure 2). Different amount of uronic acids were found in the beverages; the highest amount were detected in juices, which accord with the well known richness of pectin and acidic polysaccharides content in raw fruits (Sila et al.2009)

Beverages consumption and dietary fibre intake in Spanish Mediterranean diet are listed in table II. Around $630 \mathrm{~mL}$ of beverages are daily per capita consumed in the Spanish diet, corresponding around $36 \%$ to alcoholic drinks. Lager beer, espresso coffee, cocoa milk and wine are the individual items most consumed. Beverages provide a total 
amount of $2.13 \mathrm{~g} / \mathrm{person} /$ day of SDF in the Spanish diet, contributing significantly to the intake of DF. The intake of DF from solid vegetable food in the Spanish diet was estimated at $18.2 \mathrm{~g}$ (Saura-Calixto \& Goñi, 2004), corresponding to $6.9 \mathrm{~g}$ of SDF. The present work raises the intake of SDF from $6.9 \mathrm{~g}$ to $8.4 \mathrm{~g}$, which represents an increase of $25 \%$ in total soluble DF and an increase of $10.4 \%$ of the total DF intake (Fig.3).

The contribution of beverages to the intake of SDF is of the same order than other plant food groups such as fruits, beverages and cereals and higher than nuts and legumes. The consumption of beverages for the adult population can be expected to be higher than the per capita data indicated in table II, which include elderly people and children. For example, a typical adult consuming 2 coffees $(100 \mathrm{~mL}), 1$ pint of beer $(500 \mathrm{~mL})$, and an apple juice $(250 \mathrm{~mL})$ per day has an intake around $2.5 \mathrm{~g}$ of SDF from these drinks, which is an important amount in terms of accounting for total intake of DF. In summary, beverages common in the diet contain appreciable amount of soluble dietary fibre contributing significantly to the intake of DF. They may have a significant role in the health effects associated to DF intake.

89 
References.

Buttriss JL, Stokes CS (2008) Dietary fibre and health: An overview Nutr Bull 33:186200

Díaz-Rubio ME, Saura-Calixto F (2009) Dietary fibre complex in beer J Am Soc Brew Chem 67:38-43

Díaz-Rubio ME, Saura-Calixto F (2007) Dietary fiber in brewed coffee J Agric Food Chem 55:1999-2003

Díaz-Rubio ME, Saura-Calixto F (2006) Dietary fiber in wine Am J Enol Vitic 57:6972

Food Standards Agency. McCance \& Widdowson's. The Composition of Foods (2004) 6th summary ed.; compiled by Food Standards Agency and Institute of Food Research; Royal Society of Chemistry: Cambridge, U.K.

Lunn J, Buttriss JL (2007) Carbohydrates and dietary fibre Nutr Bul 32:21-64

Mañas E, Bravo L, Saura-Calixto F (1994) Sources of error in dietary fibre analysis Food Chem 50:331-342

Moreiras O, Carbajal A, Cabrera L (1995) Tablas de composición de alimentos Tablas de Composición de Alimentos

Saura-Calixto FD, Goñi I (2004) The intake of dietary indigestible fraction in the Spanish diet shows the limitations of dietary fibre data for nutritional studies Eur J Clin Nutr 58:1078-1082

Schols H, Bakx E, Schipper D, Voragen AJ (1995) A xylogalacturonan subunit present in the modified hairy regions of apple pectin Carbohydr Res 279:265-279

Sila DN, Van Buggenhout S, Duvetter T, Fraeye I, De Roeck A.Van Loey A, Hendrickx M (2009) Pectins in Processed Fruits and Vegetables: Part IIStructure-Function Relationships Compr Rev Food Sci Food Saf 8(2):86-104 

MAPA. (2009). La Alimentación en España. Ministerio de Medioambiente y Medio

123 Rural y Marino. http://www.mapa.es/es/alimentacion/pags/consumo/consumo.htm.

124

125

126

127

128

129

130

131

132

133

134

135

136

137

138

139

140

141

142

143

144

145

146 
148 Table I. Content of soluble dietary fibre (SDF) in beverages ${ }^{\mathrm{a}}$

\begin{tabular}{|c|c|c|c|c|}
\hline & Type of beverage & $\mathrm{UA}(\mathrm{g} / \mathrm{L})^{\mathrm{b}}$ & $\mathrm{NS}(\mathrm{g} / \mathrm{L})^{\mathrm{c}}$ & SDF (g/L) \\
\hline \multirow{10}{*}{ Juices } & Apple & $0.53 \pm 0.01$ & $0.57 \pm 0.01$ & $1.10 \pm 0.01$ \\
\hline & Commercial orange & $0.10 \pm 0.01$ & $1.17 \pm 0.01$ & $1.27 \pm 0.01$ \\
\hline & Orange & $0.14 \pm 0.01$ & $2.23 \pm 0.02$ & $2.37 \pm 0,02$ \\
\hline & Orange and soy & $1.11 \pm 0.01$ & $1.25 \pm 0.08$ & $2.36 \pm 0.08$ \\
\hline & Pineapple & $0.04+0.01$ & $0.74+0.07$ & $0.79 \pm 0.07$ \\
\hline & Pineapple and grape & $0.06 \pm 0.01$ & $0.43 \pm 0.01$ & $0.49 \pm 0.01$ \\
\hline & Peach & $0.53 \pm 0.01$ & $2.29 \pm 0.06$ & $2.82 \pm 0.06$ \\
\hline & Peach and grape & $0.41 \pm 0.01$ & $2.23 \pm 0.02$ & $2.64 \pm 0.02$ \\
\hline & Grape & $0.09 \pm 0.01$ & $0.27 \pm 0.01$ & $0.36 \pm 0.01$ \\
\hline & Tomato & $1.78+0.01$ & $2.98+0.1$ & $4.76+0.1$ \\
\hline \multirow{6}{*}{$\begin{array}{l}\text { Alcoholic } \\
\text { Beverages }\end{array}$} & Red wine & $0.17 \pm 0.01$ & $1.74 \pm 0.01$ & $1.91 \pm 0.01$ \\
\hline & White wine & $0.06 \pm 0.001$ & $0.12 \pm 0.001$ & $0.18+0.002$ \\
\hline & Cider & $0.01 \pm 0.001$ & $0.22 \pm 0.01$ & $0.23 \pm 0.01$ \\
\hline & Alcohol free beer & $0.03 \pm 0.001$ & $1.06 \pm 0.06$ & $1.09 \pm 0.06$ \\
\hline & Lager beer & $0.03 \pm 0.001$ & $2.05 \pm 0.05$ & $2.08 \pm 0.04$ \\
\hline & Dark Beer & $0.03+0.001$ & $3.51 \pm 0.02$ & $3.54 \pm 0.02$ \\
\hline \multirow{6}{*}{$\begin{array}{l}\text { Coffee and } \\
\text { Infusions }\end{array}$} & Red tea & $0.06 \pm 0.003$ & $1.07 \pm 0.05$ & $1.13 \pm 0.05$ \\
\hline & Instant coffee & $0.02 \pm 0.004$ & $8.99 \pm 0.4$ & $9.01 \pm 0.40$ \\
\hline & Expresso coffee & $0.01 \pm 0.004$ & $8.30 \pm 0.30$ & $8.32 \pm 0.30$ \\
\hline & Filter coffee & $0.09 \pm 0.003$ & $5.26 \pm 0.07$ & $6.01 \pm 0.07$ \\
\hline & Mint tea & negligible & $0.16 \pm 0.02$ & $0.16 \pm 0.02$ \\
\hline & Camomile tea & $0.07 \pm 0.001$ & $0.01 \pm 0.01$ & $0.08 \pm 0.01$ \\
\hline \multirow{6}{*}{$\begin{array}{l}\text { Soft dirnks } \\
\text { and others }\end{array}$} & Coke & negligible & negligible & negligible \\
\hline & Isotonic drink & negligible & negligible & negligible \\
\hline & Tonic water & negligible & negligible & negligible \\
\hline & Orange drink & $0.11 \pm 0.02$ & $0.13 \pm 0.04$ & $0.24 \pm 0.04$ \\
\hline & Tigger nut milk & negligible & $1.50 \pm 0.09$ & $1.50 \pm 0.09$ \\
\hline & Cocoa milk drink & $0.15 \pm 0.04$ & $7.22+0.2$ & $7.36+0.2$ \\
\hline
\end{tabular}

$150 \quad{ }^{a}$ Results are expressed as mean values \pm standard deviation. Comparison of means of three 151 measurements, using a significance level of $\mathrm{p}<0.05$, was performed by one-way analysis of 152 variance (ANOVA) using the Statgraphics Computer System, version 5.1.

$153{ }^{\mathrm{b}}$ Uronic acids. ${ }^{\mathrm{c}}$ Neutral sugars. 
156 Spanish Mediterranean diet

157

\begin{tabular}{|c|c|c|c|}
\hline \multicolumn{2}{|c|}{ Type of beverage } & $\begin{array}{c}\text { Consumption }^{\mathrm{a}} \\
\text { (ml/person/day) }\end{array}$ & $\begin{array}{c}\text { SDF } \\
\text { (g/person/day) } \\
\end{array}$ \\
\hline \multirow{4}{*}{ Juices } & Comercial Orange & 10.55 & 0.013 \\
\hline & Pineapple & 10.67 & 0.030 \\
\hline & Peach & 8.55 & 0.070 \\
\hline & Others $^{\text {b }}$ & 14.48 & 0.020 \\
\hline \multirow{5}{*}{$\begin{array}{l}\text { Alcoholic } \\
\text { Beverages }\end{array}$} & Alcohol free beer & 30.81 & 0.033 \\
\hline & Lager beer & 126.01 & 0.260 \\
\hline & White wine & 13.28 & 0.002 \\
\hline & Red wine & 32.6 & 0.062 \\
\hline & Others $^{\mathrm{c}}$ & 24.79 & 0.021 \\
\hline \multirow{4}{*}{$\begin{array}{l}\text { Coffee and } \\
\text { Infusions }\end{array}$} & Instant coffee & 22 & 0.198 \\
\hline & Espresso coffee & 81 & 0.670 \\
\hline & Filtered coffee & 20 & 0.110 \\
\hline & Tea and others ${ }^{d}$ & 20 & 0.002 \\
\hline \multirow{4}{*}{$\begin{array}{l}\text { Soft dirnks } \\
\text { and others }\end{array}$} & Cocoa milk drink & 85.01 & 0.620 \\
\hline & Orange drink & 35.1 & 0.008 \\
\hline & Others $^{\mathrm{e}}$ & 98.15 & 0.009 \\
\hline & TOTAL & 633 & 2.1284 \\
\hline
\end{tabular}

${ }^{\text {a }}$ Spanish National food consumption data (MAPA, 2009).

b Total consumption and SDF mean value of juices : apple, natural orange, orange and soy,

161 pineapple and grape, peach and grape, tomato .

$162^{\mathrm{c}}$ Total consumption and SDF mean value of dark beer, alcohol-free beer and natural cider.

$163{ }^{\mathrm{d}}$ Total consumption and SDF mean value of red tea, mint tea, chamomile tea

$164{ }^{\mathrm{e}}$ Total consumption and SDF mean value of tigger nut and soft drinks. 
170 Figure 1. Schematic procedure for dietary fibre determination in beverages and liquid 171 samples.

172 Figure 2.Neutral sugars composition of selected beverages analyzed in the hydrolysates 173 by gas-liquid chromatography.

174 Figure 3. Contribution of beverages to the intake of soluble dietary fibre in the Spanish 175 Mediterranean diet.

176 
193 Figure 1. Schematic procedure

194

195

196

197

198

199

200

201

202

203

204

205

206

207

208

209

210

211

212

213

214

215

216

217

218

219

220

${ }^{\mathrm{a}}$ Except for infusions, cocoa drink and coffee.

Hydrolysed beverage

Pepsin $\left(\mathrm{pH} 1.5,40 \mathrm{~min}, 40^{\circ} \mathrm{C}\right)$

2. $\alpha$-amylase $\left(\mathrm{pH} 6.9,3 \mathrm{~h}, 37^{\circ} \mathrm{C}\right)$

3. Amyloglucosidase ( $\mathrm{pH} 4.75,45$ $\min , 60^{\circ} \mathrm{C}$ )

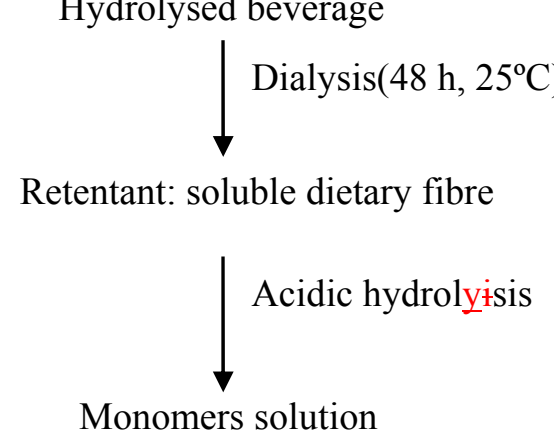

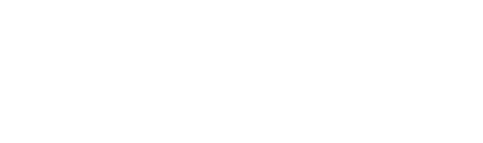
(Spectrophotometric and chromatographic determination)

Soluble dietary fibre content 
221 Figure 2. Neutral sugar composition of dietary fibre component of selected beverages Figure 2. Neutral sugar composition of dietary fibre component of selected beverages

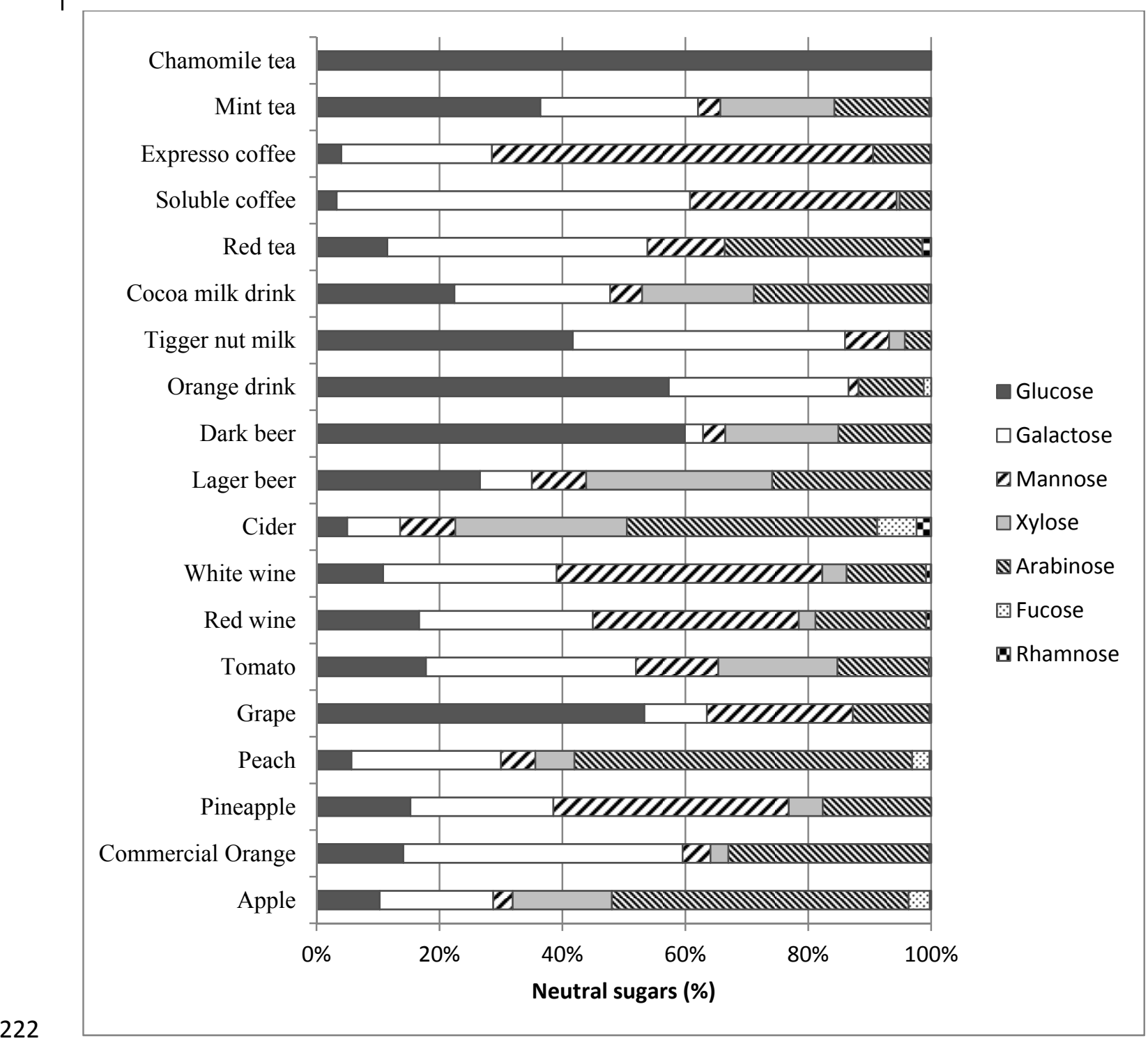


232 Figure 3. Contribution of plant food and beverages to the intake of SDF in Spanish diet ${ }^{\mathrm{a}}$

233

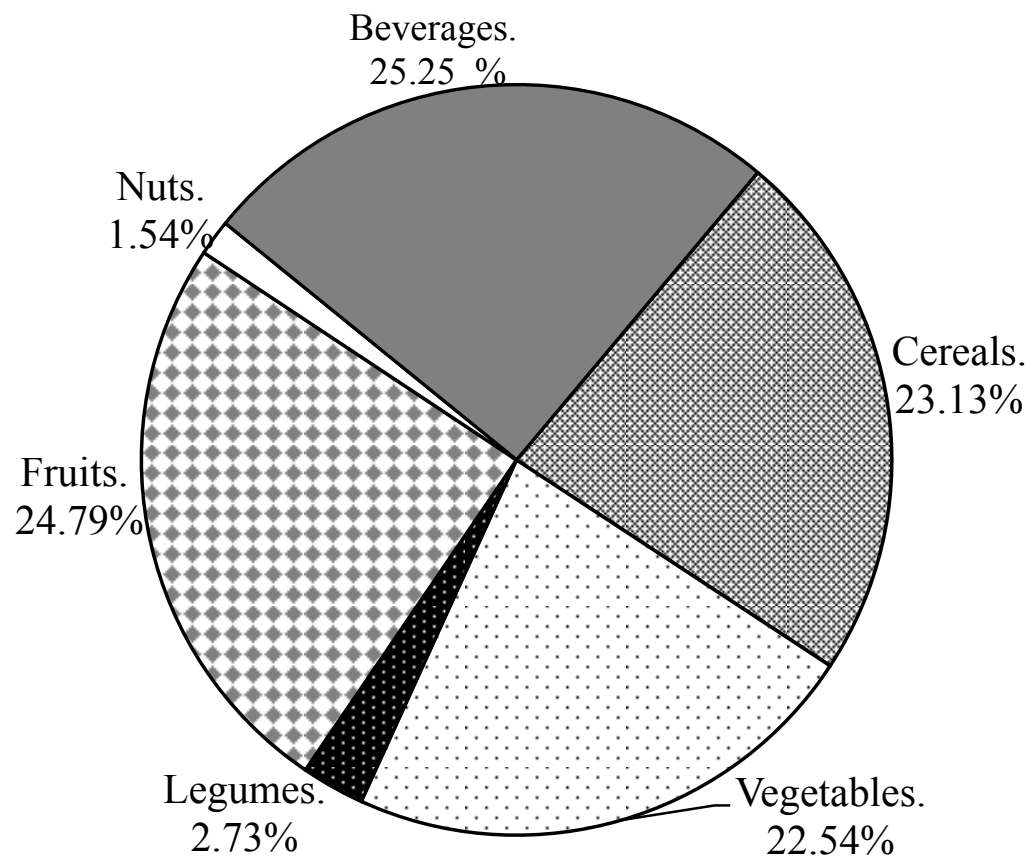

234

235

236

${ }^{a}$ Data were taken from Saura-Calixto \& Goñi (2004) and Spanish National food 237 consumption data (MAPA,2009).

238 